\title{
Borderline ovarian tumours: management in the era of fertility-sparing
} surgery

\author{
Mattia Maramai ${ }^{1,2}$, Fabio Barra ${ }^{1,2}$, Mario Valenzano Menada ${ }^{1,2}$, Sara Stigliani ${ }^{1,2}$, Melita Moioli ${ }^{2}$, Sergio Costantini ${ }^{1,2}$ and \\ Simone Ferrero ${ }^{1,2}$
}

${ }^{1}$ Department of Neurosciences, Rehabilitation, Ophthalmology, Genetics, Maternal and Child Health (DiNOGMI), University of Genova, Italy

${ }^{2}$ Academic Unit of Obstetrics and Gynaecology, IRCCS Ospedale Policlinico San Martino, Genova, Italy

\begin{abstract}
Borderline ovarian tumours (BOTs) are ovarian neoplasms characterised by epithelial proliferation, variable nuclear atypia and no evidence of destructive stromal invasion. BOTs account for approximately $15 \%$ of all epithelial ovarian cancers. Due to the fact that the majority of BOTs occur in women under 40 years of age, their surgical management often has to consider fertility-sparing approaches. The aim of this mini-review is to discuss the state of the art of fertility-sparing surgery for BOTs with a specific focus on the extent of surgery, post-operative management and fertility.
\end{abstract}

Keywords: ovarian neoplasms, ovarian cysts, fertility preservation, salpingo-oophorectomy

\section{Introduction}

Borderline ovarian tumours (BOTs) are a group of ovarian neoplasms described as 'semimalignant disease' for the first time by Taylor [1] in 1929. BOTs are characterised by higher epithelial proliferation and more variable nuclear atypia than benign lesions; however, they have not stromal invasion, in contrast to carcinomas [2]. The vast majority of BOTs have serous or mucinous histotypes; other rare types are clear-cell, endometrioid and Brenner (transitional-cell) tumours. Despite the lack of stromal invasion, serous BOTs may present implants on peritoneal surfaces, which in a small percentage of cases, invade underlying tissue. In the presence of invasive implants, according to the 2014 WHO (World Health Organization) Classification of Tumours of Female Reproductive Organs, BOTs should be considered as low-grade serous carcinoma [2, 3].

BOTs account for approximately $15 \%$ of all epithelial ovarian cancers, with an annual prevalence of 1.8-4.8/100,000 [4, 5]. Overall, being characterised by a less aggressive biological behaviour, BOTs have a better prognosis than malignant epithelial ovarian cancers; in fact, studies with long term follow-up describe 5-year survival rates over $90 \%$ [6-8]. Additionally, compared to malignant ovarian cancers, these tumours tend to more
Correspondence to: Fabio Barra Email: fabio.barra@icloud.com

ecancer 2020, 14:1031 https://doi.org/10.3332/ecancer.2020.1031

Published: 06/05/2020

Received: 27/12/2019

Publication costs for this article were supported by ecancer (UK Charity number 1176307).

Copyright: ( $)$ the authors; licensee ecancermedicalscience. This is an Open Access article distributed under the terms of the Creative Commons Attribution License (http:// creativecommons.org/licenses/by/3.0), which permits unrestricted use, distribution, and reproduction in any medium, provided the original work is properly cited. 
frequently occur in younger patients and at an earlier stage: more than a third of BOTs occur in women younger than 40 years of age, in contrast to malignant epithelial ovarian cancers, whose incidence is about $6 \%$ in the same age group. In two large series by Trillsh and du Bois, the diagnosis of BOTs was done at stage I in $78 \%-82 \%$ of cases $[9,10]$. Several studies reported increasing in BOTs survival rates from 60 's to present, probably due to the common misclassification with carcinomas; in fact, BOTs had a first specific definition by WHO in 1973; the same studies reported an increase in their incidence in the same period as well [4]; these reports could be partly attributed to a rising awareness of the distinctive pathologic features of BOTs $[2,11]$.

Surgery is the primary treatment for BOTs. Similarly to the management of malignant ovarian cancers, the extent of surgery depends on stage: for stage I disease, the therapeutic approach should include a surgical staging with total hysterectomy, bilateral salpingo-oophorectomy, omentectomy, peritoneal washing and multiple biopsies; appendix should be removed in case of mucinous histology [12, 13]. In patients with evidence of advanced stage, all visible disease should be surgically removed $[12,14]$. The use of minimally invasive or traditional open techniques has been evaluated in the current literature: a series of 105 patients treated by Trillsch et al [15] demonstrated no statistically significant differences in achieving a complete surgical cytoreduction by laparoscopy or laparotomy; moreover, the authors found an advantage in performing a complete surgical staging during primary surgery by laparotomy although these data equalised after re-staging procedures. Another series by Desfeux et al [16] reported no difference in recurrence rates and similar survival curves across these surgical approaches. For this reason, minimally invasive surgery is considered feasible and safe in the management of patients affected by BOTs. Casarin et al [17] analysed the impact of adnexal size on the risk of surgical spillage: in their retrospective analysis, adnexa larger than $10 \mathrm{~cm}$ in maximum diameter were associated with a 4 -fold risk of surgical spillage with laparoscopic approach (54.5\% versus $12.1 \%$ ) compared to open surgery. In the sub-analysis of patients treated by laparoscopy, they found a positive correlation between the adnexa size and surgical conversion rates $(p$ $=0.003)$, need for mini laparotomy for retrieving the specimens $(p=0.006)$ and global operative time $(p<0.001)$. Nevertheless, laparoscopy obtained less intraoperative blood loss $(p=0.007)$ and shorter operative time $(p<0.001)$.

The increasing use of robotic surgery in gynaecology was focalised also on the management of early-stage ovarian cancer and BOTs. In fact, the robotic-assisted approach is useful and safe in patients with presumed early stage disease [18]. In a retrospective analysis of 39 patients treated by minimally invasive surgery for presumed early-stage ovarian cancer, Bellia et al [19] showed no significant difference between laparoscopic versus robotic management in terms of operating time, needs for blood transfusion, intra- and post-operative complications and number of lymph nodes detected. Similar results were found by Nehzat et al [20] in a retrospective analysis of 63 patients with a presumed stage I ovarian cancer who underwent minimally invasive surgery. No difference was found in terms of estimated blood loss, length of stay and operative time.

Overall, the choice of surgical approach for BOTs should consider size of ovarian masses, presence and localisation of peritoneal implants, presence of bulky nodes, surgeon's skills and patient's individual characteristics [21,22]. Another topic for debate on surgical management of early-stage BOTs is represented by the need for systematic lymphadenectomy: in a retrospective analysis by Matsuo et al [23], no difference was found in survival rates in patient undergoing lymphadenectomy. Despite extreme variability among the various series, up to $40 \%-50 \%$ of lymph node involvement has been reported in BOTs [24, 25]. However, the presence of positive lymph nodes does not seem to affect global recurrence and patient's overall survival [23,25]. For this reason, the vast majority of investigators do not recommend routine pelvic and para-aortic lymphadenectomy for managing these tumours; otherwise, the removal of bulky suspicious nodes is suggested [24, 26]. The role of intra-operative frozen section (FS) during surgical management of BOTs is under debate: a retrospective analysis by Ureyen et al [27] reported a significative difference in concordance between $\mathrm{FS}$ and definitive diagnosis in serous and mucinous histologies (92\% versus $62 \%$ ); a wide decrease in concordance were found also in ovarian masses larger than $100 \mathrm{~mm}$ (90\% versus 68\%). Another paper from a tertiary referral centre highlighted that in older patients, under-diagnosis of borderline histology after FS rises from $33.3 \%$ to $53.3 \%$ [28]. In a retrospective study Shah et al [29] analysed concordance between FS diagnosis and final pathologic diagnosis of BOTs when performed in an academic hospital with a gynaecologic pathologist, an academic hospital with a nongynaecological pathologist and a community hospital with a nongynaecological pathologist; no significative differences were shown regardless of hospital type [29]. Globally considering the evidence from the literature, the use of FS in suspicious ovarian masses appears to reliably distinguish benign from malignant lesions. However, as reported above, its use in BOTs needs more caution, especially in cases of mucinous histology, large masses and older patients [30]. In cases of incomplete surgical staging at primary surgery, re-intervention for achieving complete staging does not likely affect survival rates related to BOTs [31]. 
Because many patients are still fertile at the time of diagnosis, not having completed the desire of childbearing, fertility-sparing surgery is considered as a relevant option in the management of BOTs. In many series published, the overall survival for patients undergoing a fertilitysparing surgery is close to $100 \%$ [10, 32-34].

\section{Fertility-sparing approach}

In woman with unilateral/bilateral ovarian involvement, fertility-sparing options include surgical procedures, such as unilateral cystectomy (US), unilateral salpingo-oophorectomy (USO), bilateral cystectomy (BC) or unilateral salpingo-oophorectomy plus contra-lateral cystectomy (USO+CC). In a French multi-centre study, including 313 patients with stage I BOTs, the recurrence rates after cystectomy, USO or BSO were $30.3 \%, 11 \%$ and $1.7 \%$, respectively [35]. In a retrospective series, De laco et al [36] analysed the surgical outcome of 168 patient with affected by BOTs treated with conservative surgery between 1985 and 2006: 35 underwent US, 50 underwent USO and 83 radical surgery; recurrence rate was $34.3 \%$ in US group, $20 \%$ in USO group and $6 \%$ in radical surgery group; moreover, patients who experienced tumour relapse did not die of this disease [36]. The authors definitively suggested cystectomy as a suitable option in younger patients or women with bilateral BOT or previous history of unilateral adnexectomy, after appropriate counselling about the risk of local relapse. Vasconcelos et al [37] published a meta-analysis on studies, including 5,105 women, 2,725 of who underwent conservative surgery for BOTs. Among patients undergoing US, BC, USO and USO+CC, the pooled recurrence estimates were, respectively, 25.3\%, 25.6\%, 12.5\%, and 26.1\%. In sub-analysis on patients with unilateral BOTs, USO performed significantly better than US with an OR for recurrence reduction of 2.2 ( $95 \% \mathrm{Cl}$ $=0.793-2.841, p<0.0001$ ). Overall, in cases of bilateral BOTs, USO+CC did not obtain an advantage compared to BC in terms of recurrence (26.1\% versus 25.6 ); therefore, less destructive approaches in this setting may be considered in order to preserve patients' fertility. Although no differences were found between conservative and radical surgery in terms of overall survival, the authors concluded that the low mortality rate precludes pooling estimation for death in relation to the different types of fertility sparing surgery; moreover, the short-term follow-up times tend to limit the interpretation of survival analysis. In this meta-analysis, the only prospective randomised controlled trial was an Italian paper published by Palomba et al [38], which compared BC and USO+CC, obtaining a significant shorter time to first recurrence in the BC group ( $p$ <.01); however, performing a regression analysis, the difference did not reach a statistical significance $(p=0.14)$; additionally, disease recurrence $(1.23$ [95\% $\mathrm{Cl}, 0.62-3.17 ; p=0.41])$ was not different between these groups.

Obtaining a biopsy from a normal appearing contra-lateral ovary is not recommended in patients undergoing surgical management for BOTs because the risk of under-diagnosis of an occult malignancy tends to be very low [33]. Furthermore, this procedure may cause adhesions that may impact negatively on fertility in $10 \%-20 \%$ of the cases; in fact, in cases of extensive biopsies, the risk of favouring the onset of iatrogenic menopause has been described [39].

The management of relapse of BOTs mostly depends on tumour location and histotype. In case of a relapse in remnant ovarian tissue, a second conservative surgery could represent a suitable treatment option in patients desiring to preserve fertility [40]; otherwise, in case of extra-ovarian relapse the surgical approach should be based on a complete cytoreductive surgery, associated with platinum/taxane-based chemotherapy in case of progression to low-grade serous carcinoma [14, 41]. Trans-vaginal ultrasonography seems to be the most effective technique in follow-up of patients treated conservatively for BOTs [42].

\section{Pregnancy rates and infertility after fertility-sparing approach}

It is difficult to exactly assess the impact of fertility-sparing treatments for BOTs on ovarian function and fertility. It has been reported that approximately $81 \%$ of women retain normal menstrual cycles after conservative surgery for BOTs [43]. As in benign diseases like endometriosis, the aim of fertility preservation after fertility-sparing surgery on the ovaries is debated [44]. In a meta-analysis by Raffi et al [45] the serum anti-Müllerian hormone (AMH) decreased by $38 \%$ after US or BC for ovarian endometriomas. Chang et al [46] also found a decrease in AMH serum levels after laparoscopic ovarian cystectomy; However, they observed a restore in AMH level after 3 months of follow-up, with no statistically difference with preoperative $\mathrm{AMH}$ levels. The same result was showed by Vignali et al [47] among patients underwent 
US or BC for ovarian endometriomas: no differences was shown between preoperative and 12-months postoperative AMH levels ( $p>0.05$ ); moreover, no differences in antral follicle count (AFC) were shown [48].

Pregnancy rates in women attempting to conceive after fertility-sparing surgery are very heterogeneous [49]. In the current literature, the main published series report pregnancy rates after treatment for early stage BOTs ranging from 30\% to 80\% [50, 51]. A retrospective analysis by Delle Marchette et al [52] did not show differences in terms of pregnancy rates with regard to surgical approach (open versus laparoscopy) or type of surgery (UC versus USO). However, the need for additional surgical procedures reduced the probability of getting pregnant by about $40 \%$ [52].

Another controversial topic is the need to use assisted reproductive techniques for improving fertility outcomes. In selected patients, induction of ovulation and in vitro fertilisation may be required after fertility-sparing surgery in order to enhance the chance of conceiving. Potential associations between ovulation-inductor drugs and BOTs have been proposed by several authors: in 1994, Rossing et al [53] highlighted the relation between the use of clomiphene and the increased risk to develop BOTs or even invasive ovarian cancer. Subsequent studies reduced the emphasis on this association, which at the moment is characterised by low evidence [54-56]. A meta-analysis by Siristatidis et al [57] showed a statistically significant correlation between controlled ovarian hyper-stimulation and ovarian cancer (RR = 1.50, 95\% $\mathrm{Cl}$ : 1.17-1.9); however, when the analysis was based only on infertile women, no significant associations were noted (RR = 1.26, 95\% $\mathrm{Cl}$ : 0.62-2.55); with regard to BOTs, no conclusions have been drawn due to not negligible study limitations, such as short follow-up period, low statistical power and absence of control groups [41].

As general rule, fertility counselling should be mandatory in the management of BOTs among women aiming to spare fertility. Patients with diagnosis of BOTs should be referred to an oncofertility centre before surgery in order to assess their reproductive status and to plan subsequent operative management $[58,59]$.

\section{Surveillance after fertility-sparing approach}

Currently, there is no universally accepted standard-of-care regarding follow-up after surgery for BOTs. In a cohort of 39 women, Uzan et al [60] reported that the vast majority of non-invasive relapse of BOTs were diagnosed by ultrasound (16/23; 69\%); CA125 elevation occurred in case of progression to invasive ovarian cancers (6/13; 46\%) [60]. Same evidence was found by Zanetta et al [42] in a cohort of 28 women experiencing a relapse of BOTs. Frequency of post-operative visits and chose of exams are mainly dependent to the institutional or physician expertise; the performance of clinical examination, ultrasonography and serum tumour markers is widely accepted. Staging Classifications and Clinical Practice Guidelines for Gynaecological Cancers, edited by the Fédération Internationale de Gynécologie et d'Obstétrique in 2000 suggest that a control visit should be carried out every three months during the first year after surgery for invasive ovarian cancer, with an increase to every four to six months and every year after the fifth year. For BOTs, this frequency can be annual [61]. As in the case of fertility-sparing surgery, the majority of relapses occur in the remnant ovary, a routinely ovarian scan by ultrasound in the hands of a skilled operator should be done; computed tomography or magnetic resonance are second-line options, although their use appears pivotal in the case of elevation of serum CA125. In a multicentre prospective study, Fisherova et al [62] analysed the outcomes of 20 patients with a previous diagnosis of BOT and a recurrent ovarian mass: in this population a subjective transvaginal ultrasonographic assessment of the recurrent ovarian mass by a skilled operator obtained a sensitivity of $94 \%$ with a false-positive rate of $33 \%$.

\section{Disease relapse after fertility-sparing approach}

The main clinical factors associated with disease relapse are advanced age at diagnosis, preoperative elevation of serum levels of CA125, presence of invasive implants and micropapillary histology [63].

Rates of relapse described after fertility sparing surgery for BOTs greatly differ in the current literature. The evidence shows that serous BOTs recurred more frequently than mucinous BOTs, despite progressing to an invasive carcinoma only in a smaller percentage of cases. In a retrospective analysis by Uzan et al. [64], 191 of 254 women (75.2\%) underwent conservative management for BOTs; the authors found 43 cases of recurrence ( 26 serous BOT, 17 mucinous BOT; $p=0.01$ ); among the women with initial diagnosis of serous BOT, only 3 (11.5\%) developed an invasive carcinoma; in contrast, among those with initial diagnosis of mucinous BOT, invasive carcinoma occurred in 9 women (52.9\%). 
Recurrence of serous BOT in residual ovary almost always has a non-invasive histology; for this reason, it should be considered as a new primary BOT and could be potentially treated by a second fertility-sparing surgery; conversely, the vast majority of invasive recurrences are characterised by extra-ovarian involvement [14,65]. For mucinous BOT the relapse on residual ovary is related to disease persistence after an incomplete primary surgery, while extra-ovarian relapse is associated with higher risk of invasive histology and poor prognosis [66-67].

In a prospective observational study, Franchi et al [68] used transvaginal ultrasonography to assess the growth of recurrent ovarian cyst. They followed up patients with previous conservatively treated BOT and new ovarian cyst until the clinical setting recommended proceeding with surgery (no evidence of metastasis, no ascites, maximum diameter of the suspected recurrent lesion < 40 mm, presence of 'ovarian crescent sign' and negative tumor marker). The median time prior to surgery was 9.8 months; the final histological report confirmed the previous histotype in all the patients [68].

\section{Surgery completion after fertility-sparing approach}

Recurrence rates in fertility-sparing surgery for BOTs are higher than after radical surgery; however, after the completion of desire of conception the surgical second look with removal of uterus and contra-lateral ovary remains debated. In fact, the published data does not report differences in terms of survival rates after completion of surgery for BOTs. For serous BOTs many authors suggest expectant management and performance of radical surgery only in cases of disease recurrence [13, 69]. For mucinous BOTs several authors suggest the completion of surgery, in fact, many mucinous tumours relapsed as invasive ovarian cancers [70]. In these young patients, psychological impact of disease should not be neglected; thus, an accurate and comprehensive preoperative fertility counselling has to be done [71].

\section{Conclusion}

Fertility sparing surgery for BOTs is feasible and does not seem to negatively influence patients' long-term survival, although higher disease recurrence rates have been reported. The extent of surgery should be individualised based on patient characteristics, tumour stage and histology. Women with a diagnosis of BOT should be referred to an oncofertility centre prior to performing fertility-sparing surgery in order to assess reproductive status and to plan future post treatment pregnancies. In these patients, a routine follow-up evaluation should be done, including clinical examination, ultrasound and dosage of serum tumour markers. Surgical management of relapse depends on disease localisation and histology.

\section{Conflicts of interest}

The authors have not conflict of interest to declare.

\section{Authors' contributions}

$\begin{array}{ll}\text { MMA } & \text { literature review, manuscript writing } \\ \text { FB } & \text { manuscript revision } \\ \text { MVM } & \text { literature review } \\ \text { SS } & \text { data analysis } \\ \text { MMO } & \text { data analysis } \\ \text { SF } & \text { manuscript revision } \\ \text { SC } & \text { supervision }\end{array}$




\section{Funding statement}

This paper has not been funded.

\section{References}

1. Taylor HC (1929) Malignant and semimalignant tumors of the ovary Surg Gynecol Obstet 48 204-230

2. Prat J (2017) Pathology of borderline and invasive cancers Best Pract Res Clin Obstet Gynaecol 41 15-30 https://doi.org/10.1016/j.bpobgyn.2016.08.007 PMID: 28277307

3. Kurman RJ, Carcangiu ML, and Herrington CS, et al (2014) WHO Classification of Tumours of Female Reproductive Organs (Lyon: IARC Press).

4. Skírnisdóttir I, Garmo H, and Wilander E, et al (2008) Borderline ovarian tumors in Sweden 1960-2005: trends in incidence and age at diagnosis compared to ovarian cancer Int J Cancer 123(8) 1897-1901 https://doi.org/10.1002/ijc.23724 PMID: 18661518

5. Akeson M, Zetterqvist BM, and Dahllöf K, et al (2008) Population-based cohort follow-up study of all patients operated for borderline ovarian tumor in western Sweden during an 11-year period Int J Gynecol Cancer 18(3) 453-459 https://doi.org/10.1111/j.15251438.2007.01051.x PMID: 18476948

6. Karlsen NMS, Karlsen MA, and Høgdall E, et al (2016) Relapse and disease specific survival in 1143 Danish women diagnosed with borderline ovarian tumours (BOT) Gynecol Oncol 142(1) 50-53 https://doi.org/10.1016/j.ygyno.2016.05.005 PMID: 27168006

7. May J, Skorupskaite K, and Congiu M, et al. (2018) Borderline ovarian tumors: fifteen years' experience at a Scottish Tertiary Cancer Center Int J Gynecol Cancer 28(9) 1683-1691 https://doi.org/10.1097/IGC.0000000000001364 PMID: 30365457

8. Lenhard MS, Mitterer S, and Kümper C, et al (2009) Long-term follow-up after ovarian borderline tumor: relapse and survival in a large patient cohort Eur J Obstet Gynecol Reprod Biol 145(2) 189-194 https://doi.org/10.1016/j.ejogrb.2009.04.031 PMID: 19477060

9. Trillsch F, Mahner S, and Ruetzel J, et al (2010) Clinical management of borderline ovarian tumors Expert Rev Anticancer Ther 10(7) 1115-1124 https://doi.org/10.1586/era.10.90 PMID: 20645700

10. du Bois A, Ewald-Riegler N, and de Gregorio N, et al (2013) Borderline tumours of the ovary: a cohort study of the Arbeitsgmeinschaft Gynäkologische Onkologie (AGO) Study Group Eur J Cancer 49(8) 1905-1914 https://doi.org/10.1016/j.ejca.2013.01.035 PMID: 23490647

11. Kalapotharakos G, Högberg T, and Bergfeldt K, et al (2016) Long-term survival in women with borderline ovarian tumors: a populationbased survey of borderline ovarian tumors in Sweden 1960-2007 Acta Obstet Gynecol Scand 95(4) 473-479 https://doi.org/10.1111/ aogs.12846

12. Colombo N, Sessa C, and du Bois A, et al (2019) ESMO-ESGO consensus conference recommendations on ovarian cancer: pathology and molecular biology, early and advanced stages, borderline tumours and recurrent disease Ann Oncol 30(5) 672-705 https://doi. org/10.1093/annonc/mdz062 PMID: 31046081

13. Cadron I, Leunen K, and Van Gorp T, et al (2007) Management of borderline ovarian neoplasms J Clin Oncol 25(20) 2928-2937 https:// doi.org/10.1200/JCO.2007.10.8076 PMID: 17617524

14. Gershenson DM (2017) Management of borderline ovarian tumours Best Pract Res Clin Obstet Gynaecol 41 49-59 https://doi. org/10.1016/j.bpobgyn.2016.09.012

15. Trillsch F, Ruetzel JD, and Herwig U, et al (2013) Surgical management and perioperative morbidity of patients with primary borderline ovarian tumor (BOT) J Ovarian Res 6(1) 48 https://doi.org/10.1186/1757-2215-6-48 PMID: 23837881 PMCID: 3708757 
16. Desfeux P, Camatte $\mathrm{S}$, and Chatellier G, et al (2005) Impact of surgical approach on the management of macroscopic early ovarian borderline tumors Gynecol Oncol 98(3) 390-395 https://doi.org/10.1016/j.ygyno.2005.04.043 PMID: 16043215

17. Casarin J, Laganà AS, and Uccella S, et al (2019) Surgical treatment of large adnexal masses: a retrospective analysis of 330 consecutive cases Minim Invasive Ther Allied Technol 1-9 https://doi.org/10.1080/13645706.2019.1649700 PMID: 31375049

18. Minig L, Padilla Iserte P, and Zorrero C, et al. (2016) Robotic surgery in women with ovarian cancer: surgical technique and evidence of clinical outcomes J Minim Invasive Gynecol 23(3) 309-316 https://doi.org/10.1016/j.jmig.2015.10.014

19. Bellia A, Vitale SG, and Laganà AS, et al (2016) Feasibility and surgical outcomes of conventional and robot-assisted laparoscopy for early-stage ovarian cancer: a retrospective, multicenter analysis Arch Gynecol Obstet 294(3) 615-622 https://doi.org/10.1007/s00404016-4087-9 PMID: 27040423

20. Nezhat FR, Finger TN, Vetere P, et al (2014) Comparison of perioperative outcomes and complication rates between conventional versus robotic-assisted laparoscopy in the evaluation and management of early, advanced, and recurrent stage ovarian, fallopian tube, and primary peritoneal cancer Int J Gynecol Cancer 24(3) 600-607 https://doi.org/10.1097/IGC.0000000000000096 PMID: 24557439

21. Maneo A, Vignali M, and Chiari S, et al (2004) Are borderline tumors of the ovary safely treated by laparoscopy? Gynecol Oncol 94(2) 387-392 https://doi.org/10.1016/j.ygyno.2004.05.003 PMID: 15297177

22. Kane A, Uzan C, and Gouy S, et al (2010) Fertility results and outcomes after pure laparoscopic management of advanced-stage serous borderline tumors of the ovary Fertil Steril 94(7) 2891-2894 https://doi.org/10.1016/j.fertnstert.2010.04.045 PMID: 20537629

23. Matsuo K, Machida H, and Takiuchi T, et al (2017) Role of hysterectomy and lymphadenectomy in the management of early-stage borderline ovarian tumors Gynecol Oncol 144(3) 496-502 https://doi.org/10.1016/j.ygyno.2017.01.019 PMID: 28131526

24. Qian XQ, Hua XP, and Wu JH, et al (2018) Clinical predictors of recurrence and prognostic value of lymph node involvement in the serous borderline ovarian tumor Int J Gynecol Cancer 28(2) 279-284 https://doi.org/10.1097/IGC.0000000000001154

25. McKenney JK, Balzer BL, and Longacre TA (2006) Lymph node involvement in ovarian serous tumors of low malignant potential (borderline tumors): pathology, prognosis, and proposed classification Am J Surg Pathol 30(5) 614-624 https://doi.org/10.1097/01. pas.0000194743.33540.e6 PMID: 16699316

26. Lesieur B, Kane A, and Duvillard P, et al (2011) Prognostic value of lymph node involvement in ovarian serous borderline tumors Am J Obstet Gynecol 204(5) 438.e1-438.e4387 https://doi.org/10.1016/j.ajog.2010.12.055

27. Ureyen I, Turan T, and Cirik DA, et al (2014) Frozen section in borderline ovarian tumors: is it reliable? Eur J Obstet Gynecol Reprod Biol 181 115-118 https://doi.org/10.1016/j.ejogrb.2014.07.039 PMID: 25145763

28. Morton R, Anderson L, and Carter J, et al (2017) Intraoperative frozen section of ovarian tumors: a 6-year review of performance and potential pitfalls in an Australian Tertiary Referral Center Int J Gynecol Cancer 27(1) 17-21 https://doi.org/10.1097/IGC.0000000000000851

29. Shah JS, Mackelvie M, and Gershenson DM, et al (2019) Accuracy of intraoperative frozen section diagnosis of borderline ovarian tumors by hospital type J Minim Invasive Gynecol 26(1) 87-93 https://doi.org/10.1016/j.jmig.2018.04.005

30. Ratnavelu ND, Brown AP, and Mallett S, et al (2016) Intraoperative frozen section analysis for the diagnosis of early stage ovarian cancer in suspicious pelvic masses Cochrane Database Syst Rev 3(3) PMID: 26930463 PMCID: 6457848

31. Shim SH, Kim SN, and Jung PS, et al (2016) Impact of surgical staging on prognosis in patients with borderline ovarian tumours: a metaanalysis Eur J Cancer 54 84-95 https://doi.org/10.1016/j.ejca.2015.11.005 PMID: 26735354

32. Zanetta G, Rota S, and Chiari S, et al (2001) Behavior of borderline tumors with particular interest to persistence, recurrence, and progression to invasive carcinoma: a prospective study J Clin Oncol 19(10) 2658-2664 https://doi.org/10.1200/JC0.2001.19.10.2658 PMID: 11352957 
33. Morice P, Camatte S, and El Hassan J, et al (2001) Clinical outcomes and fertility after conservative treatment of ovarian borderline tumors Fertil Steril 75(1) 92-96 https://doi.org/10.1016/S0015-0282(00)01633-2 PMID: 11163822

34. Mandelbaum RS, Blake EA, and Machida $\mathrm{H}$, et al (2019) Utero-ovarian preservation and overall survival of young women with early-stage borderline ovarian tumors Arch Gynecol Obstet 299(6) 1651-1658 https://doi.org/10.1007/s00404-019-05121-z PMID: 30923905

35. Poncelet C, Fauvet R, and Boccara J, et al (2006) Recurrence after cystectomy for borderline ovarian tumors: results of a French multicenter study Ann Surg Oncol 13(4) 565-571 https://doi.org/10.1245/ASO.2006.12.024 PMID: 16491337

36. De laco P, Ferrero A, and Rosati F, et al (2009) Behaviour of ovarian tumors of low malignant potential treated with conservative surgery Eur J Surg Oncol 35(6) 643-648 https://doi.org/10.1016/j.ejso.2008.09.011

37. Vasconcelos I and de Sousa Mendes M (2015) Conservative surgery in ovarian borderline tumours: a meta-analysis with emphasis on recurrence risk Eur J Cancer 51(5) 620-631 https://doi.org/10.1016/j.ejca.2015.01.004 PMID: 25661104

38. Palomba S, Falbo A, and Del Negro S, et al (2010) Ultra-conservative fertility-sparing strategy for bilateral borderline ovarian tumours: an 11-year follow-up Hum Reprod 25(8) 1966-1972 https://doi.org/10.1093/humrep/deq159 PMID: 20573679

39. Weinstein D and Polishuk WZ (1975) The role of wedge resection of the ovary as a cause for mechanical sterility Surg Gynecol Obstet 141(3) 417-418 PMID: 1162571

40. Fischerova D, Zikan M, and Dundr P, et al (2012) Diagnosis, treatment, and follow-up of borderline ovarian tumors Oncologist 17(12) 1515-1533 https://doi.org/10.1634/theoncologist.2012-0139 PMID: 23024155 PMCID: 3528384

41. Seong SJ, Kim DH, and Kim MK, et al (2015) Controversies in borderline ovarian tumors J Gynecol Oncol 26(4) 343-349 https://doi. org/10.3802/jgo.2015.26.4.343 PMID: 26404125 PMCID: 4620372

42. Zanetta G, Rota S, and Lissoni A, et al (2001) Ultrasound, physical examination, and CA 125 measurement for the detection of recurrence after conservative surgery for early borderline ovarian tumors Gynecol Oncol 81(1) 63-66 https://doi.org/10.1006/gyno.2000.6099 PMID: 11277651

43. Morris RT, Gershenson DM, and Silva EG, et al (2000) Outcome and reproductive function after conservative surgery for borderline ovarian tumors Obstet Gynecol 95(4) 541-547 PMID: 10725486

44. Sleiman Z, Karaman E, and Terzic M, et al (2019) Fertility preservation in benign gynecological diseases: current approaches and future perspectives J Reprod Infertil 20(4) 201-208

45. Raffi F, Metwally M, and Amer S (2012) The impact of excision of ovarian endometrioma on ovarian reserve: a systematic review and meta-analysis J Clin Endocrinol Metab 97(9) 3146-3154 https://doi.org/10.1210/jc.2012-1558 PMID: 22723324

46. Chang HJ, Han SH, and Lee JR, et al (2010) Impact of laparoscopic cystectomy on ovarian reserve: serial changes of serum anti-Müllerian hormone levels Fertil Steril 94(1) 343-349 https://doi.org/10.1016/j.fertnstert.2009.02.022

47. Vignali M, Mabrouk M, and Ciocca E, et al (2015) Surgical excision of ovarian endometriomas: does it truly impair ovarian reserve? Long term anti-Müllerian hormone (AMH) changes after surgery J Obstet Gynaecol Res 41(11) 1773-1778 https://doi.org/10.1111/ jog.12830 PMID: 26420658

48. Muzii L, Di Tucci C, and Di Feliciantonio M, et al (2014) The effect of surgery for endometrioma on ovarian reserve evaluated by antral follicle count: a systematic review and meta-analysis Hum Reprod 29(10) 2190-2198 https://doi.org/10.1093/humrep/deu199 PMID: 25085800

49. Daraï E, Fauvet R, and Uzan C, et al (2013) Fertility and borderline ovarian tumor: a systematic review of conservative management, risk of recurrence and alternative options Hum Reprod Update 19(2) 151-166 https://doi.org/10.1093/humupd/dms047

50. Song T, Hun Choi C, and Lee YY, et al (2011) Oncologic and reproductive outcomes of cystectomy compared with oophorectomy as a treatment for borderline ovarian tumours Hum Reprod 26(8) 2008-2014 https://doi.org/10.1093/humrep/der119 PMID: 21511712 
51. Fauvet R, Poncelet C, and Boccara J, et al (2005) Fertility after conservative treatment for borderline ovarian tumors: a French multicenter study Fertil Steril 83(2) 284-526 https://doi.org/10.1016/j.fertnstert.2004.10.009 PMID: 15705364

52. Delle Marchette M, Ceppi L, and Andreano A, et al (2019) Oncologic and fertility impact of surgical approach for borderline ovarian tumours treated with fertility sparing surgery Eur J Cancer 111 61-68 https://doi.org/10.1016/j.ejca.2019.01.021 PMID: 30826658

53. Rossing MA, Daling JR, and Weiss NS, et al (1994) Ovarian tumors in a cohort of infertile women N Engl J Med 331(12) 771-776 https:// doi.org/10.1056/NEJM199409223311204 PMID: 8065405

54. Lundberg FE, Johansson ALV, and Rodriguez-Wallberg K, et al (2019) Assisted reproductive technology and risk of ovarian cancer and borderline tumors in parous women: a population-based cohort study Eur J Epidemiol 34(11) 1093-1101 https://doi.org/10.1007/ s10654-019-00540-3 PMID: 31377935 PMCID: 6861355

55. Lerner-Geva L, Rabinovici J, and Olmer L, et al (2013) Are infertility treatments a potential risk factor for cancer development? Perspective of 30 years of follow-up Gynecol Endocrinol 29(4) 400.

56. van Leeuwen FE, Klip H, and Mooij TM, et al (2011) Risk of borderline and invasive ovarian tumours after ovarian stimulation for in vitro fertilization in a large Dutch cohort Hum Reprod 26(12) 3456-3465 https://doi.org/10.1093/humrep/der322 PMID: 22031719 PMCID: 3212878

57. Siristatidis C, Sergentanis TN, and Kanavidis P, et al (2013) Controlled ovarian hyperstimulation for IVF: impact on ovarian, endometrial and cervical cancer - a systematic review and meta-analysis Hum Reprod Update 19(2) 105-123 https://doi.org/10.1093/humupd/ dms051

58. Mangili G, Somigliana E, and Giorgione V, et al (2016) Fertility preservation in women with borderline ovarian tumours Cancer Treat Rev 49 13-24 https://doi.org/10.1016/j.ctrv.2016.06.010 PMID: 27428850

59. Del Pup L, Peccatori FA, and Levi-Setti PE, et al (2018) Risk of cancer after assisted reproduction: a review of the available evidences and guidance to fertility counselors Eur Rev Med Pharmacol Sci 22(22) 8042-8059 PMID: 30536354

60. Uzan C, Kane A, and Rey A, et al (2011) How to follow up advanced-stage borderline tumours? Mode of diagnosis of recurrence in a large series stage II-III serous borderline tumours of the ovary Ann Oncol 22(3) 631-635 https://doi.org/10.1093/annonc/mdq414

61. Benedet JL, Bender $\mathrm{H}$, and Jones $\mathrm{H}$ 3rd, et al (2000) FIGO staging classifications and clinical practice guidelines in the management of gynecologic cancers-FIGO Committee on Gynecologic Oncology Int J Gynaecol Obstet 70(2) 209-262 https://doi.org/10.1016/S00207292(00)90001-8 PMID: 11041682

62. Fischerova D, Franchi D, and Testa A, et al (2010) Ultrasound in diagnosis of new and borderline ovarian tumors Ultrasound Obstet Gynecol 36(suppl. 1) https://doi.org/10.1002/uog.7771

63. Shih KK, Zhou Q, and Huh J, et al (2011) Risk factors for recurrence of ovarian borderline tumors Gynecol Oncol 120(3) 480-484 https:// doi.org/10.1016/j.ygyno.2010.11.016

64. Uzan C, Nikpayam M, and Ribassin-Majed L, et al (2014) Influence of histological subtypes on the risk of an invasive recurrence in a large series of stage I borderline ovarian tumor including 191 conservative treatments Ann Oncol 25(7) 1312-1319 https://doi. org/10.1093/annonc/mdu139 PMID: 24713312

65. Sobiczewski P, Kupryjanczyk J, and Michalski W, et al (2016) The evaluation of risk factors associated with relapse and recurrence of borderline ovarian tumors with long-term follow-up Int J Gynecol Cancer 26(6) 1053-1061 https://doi.org/10.1097/ IGC. 0000000000000722 PMID: 27177283

66. Khunamornpong S, Settakorn J, and Sukpan K, et al (2011) Mucinous tumor of low malignant potential ("borderline" or "atypical proliferative" tumor) of the ovary: a study of 171 cases with the assessment of intraepithelial carcinoma and microinvasion Int J Gynecol Pathol 30(3) 218-230 https://doi.org/10.1097/PGP.0b013e3181fcf01a PMID: 21464732 
67. Trillsch F, Mahner S, and Woelber L, et al (2014) Age-dependent differences in borderline ovarian tumours (BOT) regarding clinical characteristics and outcome: results from a sub-analysis of the Arbeitsgemeinschaft Gynaekologische Onkologie (AGO) ROBOT study Ann Oncol 25(7) 1320-1327 https://doi.org/10.1093/annonc/mdu119 PMID: 24618151

68. Franchi D, Boveri S, and Radice D, et al (2016) Ultrasonographic diagnosis and longitudinal follow-up of recurrences after conservative surgery for borderline ovarian tumors Am J Obstet Gynecol 215(6) 756.e1-756.e9 https://doi.org/10.1016/j.ajog.2016.07.024

69. Tinelli R, Tinelli A, and Tinelli FG, et al (2006) Conservative surgery for borderline ovarian tumors: a review Gynecol Oncol 100(1) 185191 https://doi.org/10.1016/j.ygyno.2005.09.021

70. Prat J (2014) The results of conservative (fertility-sparing) treatment in borderline ovarian tumors vary depending on age and histological type Ann Oncol 25(7) 1255-1258 https://doi.org/10.1093/annonc/mdu160 PMID: 24782452

71. Uzan C, Muller E, and Kane A, et al (2013) Fertility sparing treatment of recurrent stage I serous borderline ovarian tumours Hum Reprod 28(12) 3222-3226 https://doi.org/10.1093/humrep/det371 PMID: 24067602 